\title{
Efficient Light Harvesters Based on the 10-(1,3-Dithiol-2-ylidene)anthracene Core
}

2013

Vol. 15, No. 16

4166-4169

\section{Pierre-Antoine Bouit, ${ }^{\dagger}$ Lourdes Infantes,${ }^{\S}$ Joaquín Calbo," Rafael Viruela,"} Enrique Ortí, ${ }^{*, \|}$ Juan Luis Delgado, ${ }^{,, \dagger}$ and Nazario Martín ${ }^{*, t, \neq}$

IMDEA-Nanociencia, Ciudad Universitaria de Cantoblanco, 28049 Madrid, Spain, Instituto de Química-Física "Rocasolano", CSIC, 28006 Madrid, Spain, Instituto de Ciencia Molecular, Universidad de Valencia, 46980 Paterna, Spain, and Departamento de Química Orgánica, Facultad de Ciencias Químicas, Universidad Complutense de Madrid, 28040 Madrid, Spain

juanluis.delgado@imdea.org; enrique.orti@uv.es;nazmar@quim.ucm.es

Received July 1, 2013

\section{ABSTRACT}

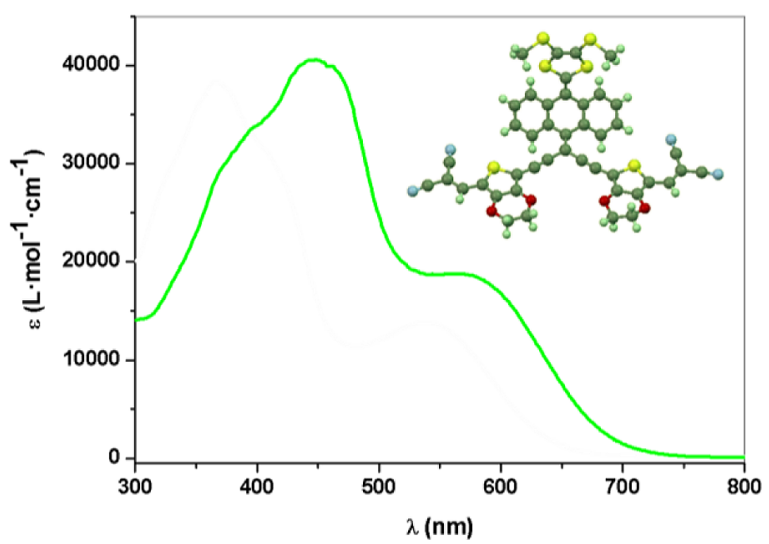

Three new push-pull chromophores based on the 10-(1,3-dithiol-2-ylidene)anthracene core were synthesized and fully characterized. The new chromophores display broad absorption spectra, nearly covering the whole visible region, with high extinction coefficients. Electrochemistry and theoretical calculations allowed the understanding of these singular electronic properties. The molecular structures were unambiguously confirmed by $\mathrm{X}$-ray diffraction.

Solar energy currently represents one of the most realistic alternatives to the use of fossil fuels. Photovoltaic devices based on organic compounds (OPV) have experienced tremendous development in the past years, ${ }^{1}$ and recently efficiencies around $8-10 \%$ have been reported. ${ }^{2}$ One of the crucial points to understanding this improvement is the careful election of suitable organic materials

\footnotetext{
$\dagger$ Imdea Nanociencia.

${ }^{\S}$ CSIC.

"Universidad de Valencia.

\$Universidad Complutense de Madrid.

(1) (a) Thompson, B. C.; Frechet, J. M. J. Angew. Chem., Int. Ed. 2008, 47, 58-77. (b) Delgado, J. L.; Bouit, P.-A.; Filippone, S.; Herranz, M. A.; Martín, N. Chem. Commun. 2010, 46, 4853-4865. (c) Li, C.-Z.; Yip, H.-L.; Jen, A. K.-Y. J. Mater. Chem. 2012, 22, 4161-4177. (d) Lin, Y.; Li, Y.; Zhan, X. Chem. Soc. Rev. 2012, 41, 4245-4272.

(2) (a) Huo, L.; Zhang, S.; Guo, X.; Xu, F.; Li, Y.; Hou, J. Angew. Chem., Int. Ed. 2011, 50,9697-9702. (b) Mishra, A.; Bäuerle, P. Angew. Chem., Int. Ed. 2012, 51, 2020-2068.
}

able to fulfill some energetic and electronic requirements. Among these requisites, the ability of the material to harvest sunlight in a broad range of the visible and NIR spectrum is essential in order to obtain a suitable photoresponse. In this regard, organic chromophores such as push-pull systems, displaying outstanding absorption properties, are promising materials to obtain highly efficient $\mathrm{OPV}^{3}$ and hybrid cells. ${ }^{4}$

In this communication, we report the synthesis and the optical and electrochemical properties of new push-pull

(3) (a) Kroneneberg, N. M.; Deppish, M.; Würthner, F.; Ledemann, H. V. A.; Deing, K.; Meerholz, K. Chem. Commun. 2008, 6489-6491. (b) Roquet, S.; Cravino, A.; Leriche, P.; Alévêque, O.; Frère, P.; Roncali, J. J. Am. Chem. Soc. 2006, 128, 3459-3466. (c) Lin, L.-Y.; Chen, Y.-H.; Huang, Z.-Y.; Lin, H.-W.; Chou, S.-H.; Lin, F.; Chen, C.-W.; Liu, Y.-H.; Wong, K.-T. J. Am. Chem. Soc. 2011, 133, 15822-15825. (d) Bouit, P.-A.; Villegas, C.; Delgado, J. L; Viruela, P.; Pou-Amérigo, R.; Ortí, E.; Martín, N. Org. Lett. 2011, 13, 604-607. 
molecules based on the 10-(1,3-dithiol-2-ylidene)anthracene core (see Scheme S1 in the Supporting Information (SI)), absorbing in a broad region of the visible spectrum. The chemical structures of the new push-pull materials have been unambiguously confirmed by singlecrystal X-ray diffraction, and their electrochemical and optical properties have been characterized with the help of density functional theory (DFT) calculations. Recently, we have described the preparation of 10-(1,3-dithiol-2ylidene)anthracene derivatives for their application in dye-sensitized solar cells. ${ }^{5}$ Molecular engineering of this appealing core allows the design of materials with improved light-harvesting properties. The new dyes synthesized here bear the same electron-donor unit, the 10-(1,3-dithiol-2-ylidene)anthracene group, but a different conjugated $\pi$-bridge, 3 ,4-ethylenedioxythiophene (EDOT) for $\mathbf{6}$ or phenyl for $\mathbf{4}$ and $\mathbf{5}$, as well as two kinds of electroaccepting units, an ester group for $\mathbf{4}$ and a dicyanovinylene group for $\mathbf{5}$ and $\mathbf{6}$ (Figure 1).

The synthesis of the key synthon 1, featuring two terminal alkyne groups (Scheme S1), was carried out in four steps in good yield. ${ }^{6}$ The conjugated bridges were then introduced by the Sonogashira cross-coupling reaction using $\mathrm{PdCl}_{2}\left(\mathrm{PPh}_{3}\right)_{2}$ and $\mathrm{CuI}$ as catalysts. The introduction of the accepting units was achieved by 2 -fold Knoevenagel condensation of aldehydes $\mathbf{2}$ and $\mathbf{3}$ with malononitrile, to afford the new dyes $\mathbf{5}$ and $\mathbf{6}$ in good to moderate yields (75\% and 50\%, respectively; see the SI). Dye 4, with the two decyl chains, displays excellent solubility in the main

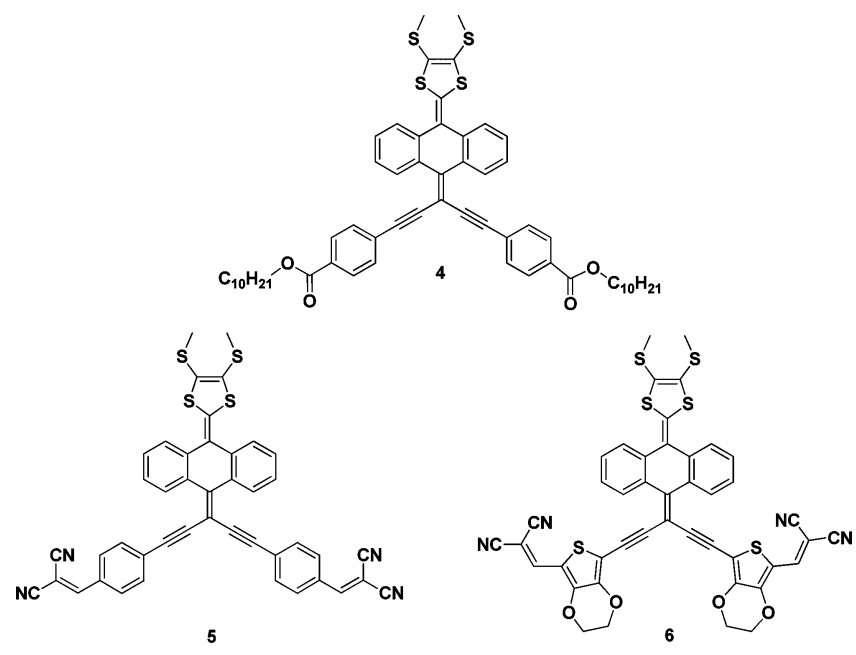

Figure 1. Push-pull systems 4, 5, and $\mathbf{6}$.

(4) (a) Kim, S.; Lee, J. K.; Kang, S. O.; Ko, J.; Yum, J. H.; Fantacci, S.; De Angelis, F.; Di Censo, D.; Nazeeruddin, M. K.; Grätzel, M. J. Am. Chem. Soc. 2006, 128, 16701-16707. (b) Wenger, S.; Bouit, P.-A.; Chen, Q.; Teuscher, J.; Di Censo, D.; Humphry-Baker, R.; Moser, J. E.; Delgado, J. L.; Martín, N.; Zakeeruddin, S. M.; Grätzel, M. J. Am. Chem. Soc. 2010, 132, 5164-5169.

(5) Bouit, P.-A; Marszalek, M.; Humphry-Baker, R.; Viruela, R.; Ortí, E.; Zakeeruddin, S.-M.; Grätzel, M.; Delgado, J. L.; Martín, N. Chem.-Eur. J. 2012, 18, 11621-11629.

(6) Chen, G.; Wang, L.; Thompson, D. W.; Zhao, Y. Org. Lett. 2008, $10,657-660$ organic solvents. The structures of all the new compounds and the new sensitizers were confirmed by ${ }^{1} \mathrm{H},{ }^{13} \mathrm{C} \mathrm{NMR}$, and high resolution mass spectrometry.

Slow evaporation of chloroform solutions of $\mathbf{2}, \mathbf{5}$, and $\mathbf{6}$ allowed the obtention of single crystals suitable for its study by X-ray diffraction (Figures 2 as well as S10 and S11 in the SI). ${ }^{7}$ The compounds adopt the typical butterfly- or saddle-like shape observed for exTTF (2-[9-(1,3-dithiol-2ylidene)anthracen-10(9H)-ylidene]-1,3-dithiole) derivatives. ${ }^{8}$ The existence of several $\mathrm{C}-\mathrm{H} \cdots \pi$ and $\pi \cdots \pi$ stacking interactions plus other weaker $\mathrm{C}-\mathrm{H} \cdot \cdots \mathrm{N} \equiv \mathrm{C}$ and $\mathrm{C}-\mathrm{H} \cdot \mathrm{S}$ hydrogen bonds led to the formation of supramolecular networks of compounds $\mathbf{2}, \mathbf{5}$, and $\mathbf{6}$.
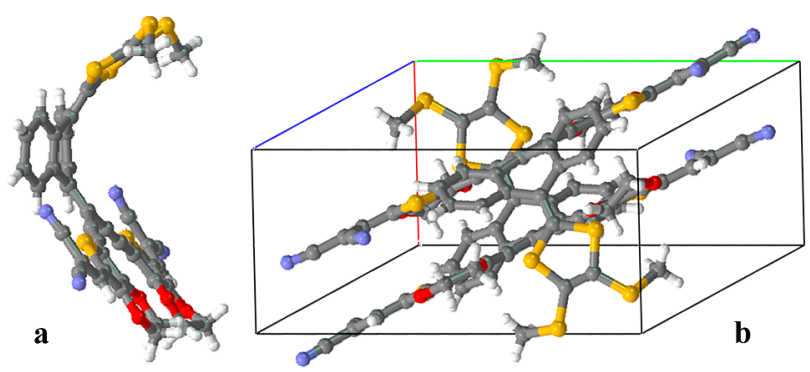

Figure 2. (a) X-ray crystal structure of 6. (b) Unit cell.

The molecular geometries of the three push-pull systems were optimized using DFT calculations at the B3LYP/ $6-31 G^{* *}$ level (see the SI for computational details). The decyl chains in $\mathbf{4}$ were replaced by a simple methyl group to simplify the calculation. As obtained from X-ray analysis, theoretical calculations predict concave saddle-like structures, in which the central ring of the anthracene unit folds up in a boat conformation and the dithiole rings are tilted down. The planes defined by the external benzene rings of the anthracene unit are predicted to form an angle of $40.5^{\circ}$ for 5 and $38.6^{\circ}$ for $\mathbf{6}$ slightly overestimating the angles obtained by $\mathrm{X}$-ray diffraction $\left(36.2^{\circ}\right.$ and $34.5^{\circ}$, respectively) due to the packing forces present in the crystal that tend to reduce the folding. The dihedral angles of $35.5^{\circ}$ computed for the dithiole tilting in $\mathbf{5}$ and $\mathbf{6}$ nicely fit the X-ray values of $34.2^{\circ}(5)$ and $34.1^{\circ}(6)$. The same considerations apply for the tilting of the acceptor moiety (see Table S1 in the SI). The acceptor arms remain mostly planar in all dyes thus favoring the $\pi$-electron communication along the acceptor moiety. This planarity is even more pronounced in the crystal due to the efficient $\pi-\pi$ coplanar interactions in the packing (see Figure $2 \mathrm{~b}$ and Table S1).

Figure 3 shows the atomic orbital (AO) composition of the highest-occupied (HOMO-2 to HOMO) and

(7) CCDC 900353 (2), CCDC 890337 (5), and CCDC 890785 (6) contain the supplementary crystallographic data for this paper. These data can be obtained free of charge from The Cambridge Crystallographic Data Centre via http://www.ccdc.cam.ac.uk/data_request/cif.

(8) Batsanov, A. S.; Bryce, M. R.; Coffin, M. A.; Green, A.; Hester, R. E.; Howard, J. A. K.; Lednev, I. K.; Martín, N.; Moore, A. J.; Moore, J. N.; Ortí, E.; Sánchez, L.; Savirón, M.; Viruela, P. M.; Viruela, R.; Ye, T.-Q. Chem.-Eur. J. 1998, 4, 2580-2592. 


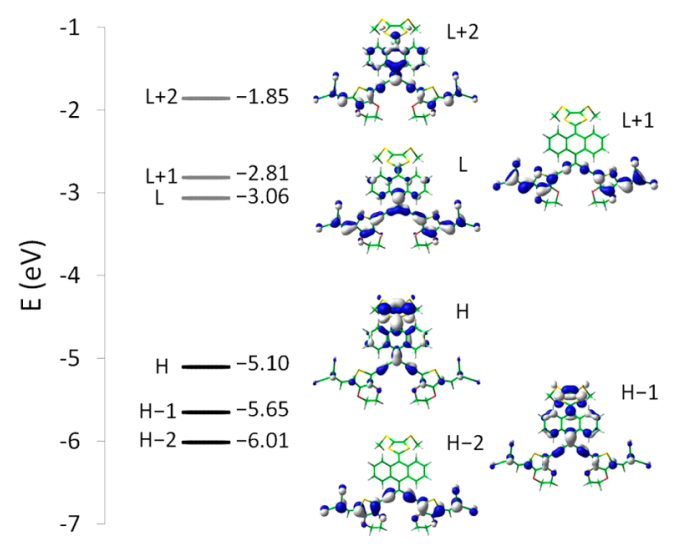

Figure 3. Electron-density contours $\left(0.03 \mathrm{e} \mathrm{bohr}^{-3}\right)$ and orbital energies calculated for the frontier molecular orbitals of 6 at the B3LYP/6-31G** level. H and L denote HOMO and LUMO, respectively.

lowest-unoccupied (LUMO to LUMO+2) molecular orbitals of 6, as a representative example, The HOMO $(-5.10 \mathrm{eV})$ and HOMO $-1(-5.65 \mathrm{eV})$ are localized on the electron-donor 10-(1,3-dithiol-2-ylidene)anthracene unit, hereafter named hemi-exTTF, whereas the HOMO-2 $(-6.01 \mathrm{eV})$ spreads over the electron-acceptor moiety with no hemi-exTTF participation. The LUMO $(-3.06 \mathrm{eV})$ and $\mathrm{LUMO}+1(-2.81 \mathrm{eV})$ are located on the electron-acceptor arms, and the LUMO $+2(-1.85 \mathrm{eV})$ comprises both the hemi-exTTF moiety and the acceptor fragment. Identical topologies are predicted for the frontier molecular orbitals of $\mathbf{4}$ and $\mathbf{5}$ (see Figure S13). A pronounced stabilization of the LUMO is predicted in passing from $\mathbf{4}(-2.46 \mathrm{eV})$ to $\mathbf{5}$ $(-3.01 \mathrm{eV})$ and $\mathbf{6}(-3.06 \mathrm{eV})$ due to the higher electronegative character of the dicyanovinylene group compared to the ester unit. The presence of the electron-donor EDOT fragment in $\mathbf{6}$ slightly increases the energy of the HOMO $(-5.10 \mathrm{eV})$ compared to $5(-5.17 \mathrm{eV})$. Theoretical calculations therefore predict small HOMO-LUMO energy gaps of $-2.64,-2.16$, and $-2.04 \mathrm{eV}$ for $\mathbf{4}, \mathbf{5}$, and $\mathbf{6}$, respectively, and suggest the presence of low-energy charge-transfer (CT) absorption bands in the electronic spectrum.

The redox properties of 4-6 were examined by cyclic voltammetry (CV) (Table 1). The anodic region of dye 4 is characterized by one reversible wave $\left(E_{\text {ox }}^{\circ}=0.27 \mathrm{~V}\right)$ attributed to the hemi-exTTF unit, whereas no reduction is observed in the experimental conditions. The presence of the stronger electron-accepting dicyanovinylene groups in 5 shifts the reduction potential to $-1.31 \mathrm{~V}$, whereas the oxidation potential is only weakly affected $\left(E^{\circ}{ }_{\text {ox }}=0.29 \mathrm{~V}\right)$. This trend nicely correlates with the slight stabilization of the HOMO $(0.07 \mathrm{eV})$ and the significant stabilization of the LUMO $(0.55 \mathrm{eV})$ predicted by theoretical calulations in passing from 4 to 5 (Figure S13). The presence of the auxiliary electron-donor EDOT groups in $\mathbf{6}$ slightly reduces the oxidation $\left(E_{\text {ox }}^{\circ}=0.25 \mathrm{~V}\right)$ and reduction $\left(E_{\text {red }}^{\circ}=\right.$ $-1.26 \mathrm{~V}$ ) potentials. CV measurements therefore obtain a decrease of the electrochemical gap along the series 4
$(>2.07 \mathrm{~V}), \mathbf{5}(1.60 \mathrm{~V})$, and $\mathbf{6}(1.51 \mathrm{~V})$, which is in perfect agreement with theoretical predictions and with the trend observed from optical data (see below).

Table 1. Electrochemical and Optical Data for 4-6

\begin{tabular}{cccccc}
\hline compd & $\begin{array}{c}E_{\text {ox }}^{\circ} \\
(\mathrm{V})^{a}\end{array}$ & $\begin{array}{c}E_{\text {red }}^{\circ} \\
(\mathrm{V})^{a}\end{array}$ & $\begin{array}{c}E_{\mathrm{g}}{ }^{\mathrm{cv}} \\
(\mathrm{V})^{b}\end{array}$ & $\begin{array}{c}\lambda_{\max } \\
(\mathrm{nm})^{c}\end{array}$ & $\begin{array}{c}\varepsilon \\
\left(\mathrm{L} \cdot \mathrm{mol}^{-1} \cdot \mathrm{cm}^{-1}\right)\end{array}$ \\
\hline $\mathbf{4}$ & 0.27 & $<-1.80$ & $>2.07$ & 491 & 19000 \\
$\mathbf{5}$ & 0.29 & -1.31 & 1.60 & 536 & 14000 \\
$\mathbf{6}$ & 0.25 & -1.26 & 1.51 & 590 & 19000
\end{tabular}

${ }^{a}$ Measured by $\mathrm{CV}\left(\mathrm{CH}_{3} \mathrm{CN}, 0.1 \mathrm{M} \mathrm{Bu}_{4} \mathrm{ClO}_{4}, v=100 \mathrm{mV} \cdot \mathrm{s}^{-1}\right.$, $\mathrm{V}$ vs $\left.\mathrm{Ag} / \mathrm{AgNO}_{3}\right) .{ }^{b}$ Electrochemical gap determined as $E_{\mathrm{OX}}-E_{\text {red. }}{ }^{c}$ Measured in DCM, $10^{-5} \mathrm{~mol} \cdot \mathrm{L}^{-1}$.

The absorption properties of compounds 4-6 were measured in dichloromethane solution (Figure 4a). 4 displays two main absorption bands in the UV and visible range $\left(\lambda_{1}=364 \mathrm{~nm} ; \lambda_{2}=491 \mathrm{~nm}\right)$. Both transitions are red-shifted, first when a better acceptor is inserted in the molecule $\left(5, \lambda_{1}=366 \mathrm{~nm} ; \lambda_{2}=536 \mathrm{~nm}\right)$, then with the
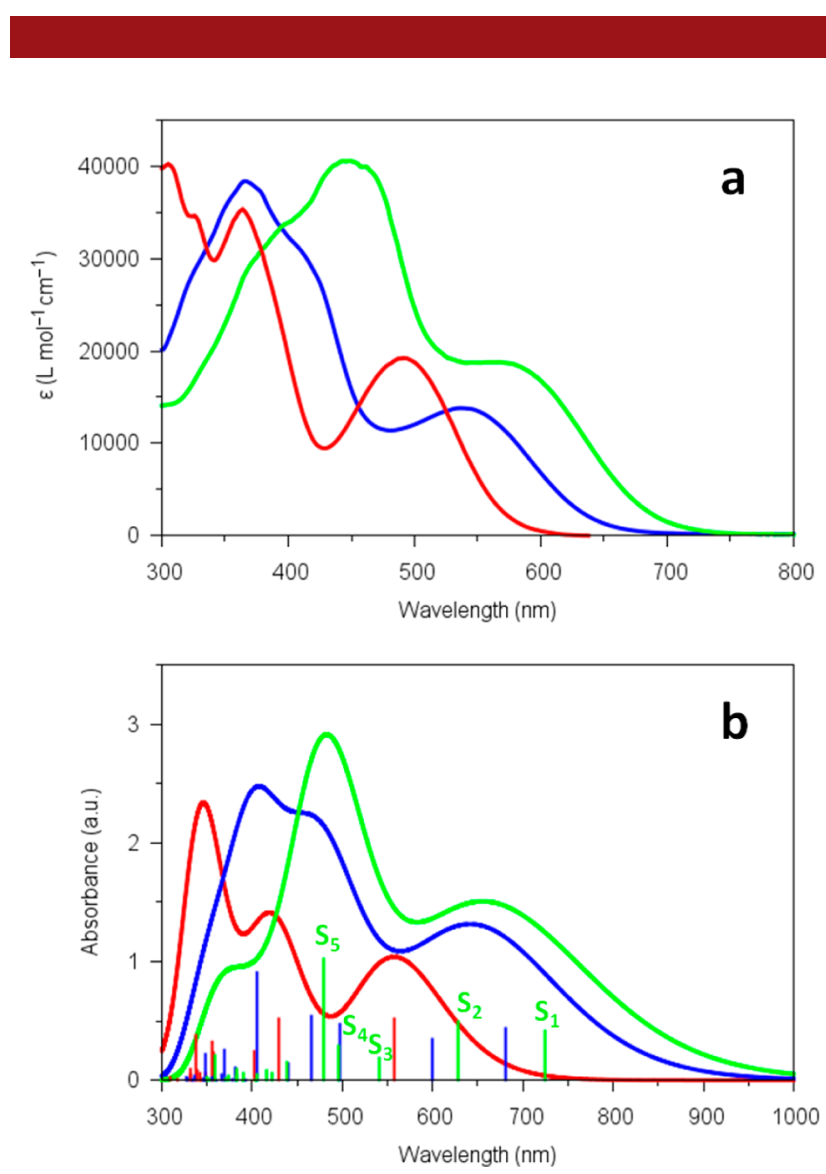

Figure 4. (a) Absorption spectra of 4 (red), 5 (blue), and 6 (green) recorded in dichloromethane at room temperature. (b) Theoretical simulation of the UV-vis absorption spectra for push-pull compounds 4-6. Vertical lines indicate the vertical excitation energies and oscillator strengths calculated for the electronic transitions to the different singlet excited states $S_{n}$. States $S_{1}$ to $S_{5}$ are explicitly denoted for compound $\mathbf{6}$. 
presence of the EDOT units $\left(\mathbf{6}, \lambda_{1}=443 \mathrm{~nm} ; \lambda_{2}=590 \mathrm{~nm}\right)$. As expected, a decrease of the optical band gap is observed when the push-pull effect in the compound is reinforced.

To investigate the nature of the electronic transitions that give rise to the absorption bands observed in the electronic spectra, the lowest-energy singlet excited states $\left(\mathrm{S}_{n}\right)$ were calculated for 4-6 using the time-dependent DFT (TD-DFT) approach. TD-DFT calculations predict that the lowest-energy absorption band observed for $\mathbf{5}$ and 6 above $500 \mathrm{~nm}$ is due to electronic transitions to the first two excited singlets $S_{1}$ and $S_{2}$ (see Table $S 2$ and Figure $4 b$ ). These states originate from the $\mathrm{HOMO} \rightarrow$ LUMO and $\mathrm{HOMO} \rightarrow \mathrm{LUMO}+1$ monoexcitations, respectively, and imply an electron density transfer from the hemi-exTTF moiety, where the HOMO resides, to the acceptor moiety, where the LUMO and LUMO+1 are mainly located (Figure 3). In compound 4, $\mathrm{S}_{2}$ stands higher in energy $(2.89 \mathrm{eV})$ due to the higher energy of the LUMO+1 (Figure S13) and does not contribute to the lowest-energy band at $491 \mathrm{~nm}$ (Figure 4b). Calculations therefore confirm the CT nature of the lowest-energy absorption band of 4-6. The moderately high intensities observed for this band are in agreement with the oscillator strengths $(f)$ around $0.4-0.5$ calculated for $S_{1}$ and $S_{2}$ (Table S2) and are due to the significant overlap between the HOMO and the $\mathrm{LUMO} / \mathrm{LUMO}+1$.

The intense absorption band observed at higher energies mainly results from the HOMO-2 $\rightarrow$ LUMO excitation (state $\mathrm{S}_{6}$ for $\mathbf{5}$ and $\mathrm{S}_{5}$ for $\mathbf{6}$, Table $\mathrm{S} 2$ and Figure $4 \mathrm{~b}$ ), which mainly implies the electron-acceptor part of the molecule (Figure 3). This electronic transition is predicted to have a high intensity $(f \approx 1.00)$ and shifts to lower energies in passing from 5 to $\mathbf{6}$ due to the EDOT groups that destabilize the HOMO-2 from -6.46 (5) to $-6.01 \mathrm{eV}(\mathbf{6})$. For compound 4, the transition is calculated to show a lower intensity $(f=0.33)$ in good agreement with the experimental spectra (Figure 4a). The HOMO $\rightarrow$ LUMO+2 excitation involving the hemi-exTTF moiety and the CT HOMO $-1 \rightarrow$ LUMO and HOMO $-1 \rightarrow$ LUMO +1 excitations also contribute to this intense absorption band (Table S2).
In summary, a new family of anthracene-based chromophores has been synthesized and fully characterized. The new dyes capture light in a broad range of the solar spectrum, compound $\mathbf{6}$ being the best light-harvesting chromophore, absorbing in the UV and visible spectrum (from 300 to $750 \mathrm{~nm}$ ). The outstanding absorption properties stem from the efficient electronic communication between the donor and acceptor moieties, giving rise to very intense charge-transfer bands. The remarkable electronic and optical properties exhibited by the new compounds make them promising materials for their further incorporation in molecular solar cells. ${ }^{9,10}$

Acknowledgment. This work has been supported by the MINECO of Spain (CTQ 2011-27934, CTQ2011-24652, CTQ2012-31914, and Consolider-Ingenio CSD 200700010 on Molecular Nanoscience), the Comunidad de Madrid (MADRISOLAR-2, S2009/PPQ-1533), the Generalitat Valenciana (Prometeo/2012/053), and the EU project (FUNMOLS FP7-212942-1). J.L.D. thanks the MINECO for a Ramón y Cajal Fellowship. P.-A.B. thanks IMDEA-Nanociencia for a postdoctoral research grant. J.C. acknowledges MECD (Spanish Ministry of Education, Culture, and Sport) for a FPU grant. L.I. thanks Comunidad de Madrid (Spain) for support (BIPEDD-2: S2010-BMD-2457).

Supporting Information Available. Synthetic procedure, chemical characterization, X-ray structures, and computational details (geometrical data and TD-DFT results). This material is available free of charge via the Internet at http://pubs.acs.org.

(9) (a) Silvestri, F.; Irwin, M. D.; Beverina, L.; Facchetti, A.; Pagani, G. A.; Marks, T. J. J. Am. Chem. Soc. 2009, 130, 17640-17641. (b) Rousseau, T.; Cravino, A.; Bura, T.; Ulrich, G.; Ziessel, R.; Roncali, J. Chem. Commun. 2009, 1673-1675.

(10) (a) Roncali, J. Acc. Chem. Res. 2009, 42, 1719-1730. (b) Bouit, P.-A.; Rauh, D.; Neugebauer, S.; Delgado, J. L.; Di Piazza, E.; Rigaut, S.; Maury, O.; Andraud, C.; Dyakonov, V.; Martín, N. Org. Lett. 2009, $11,4806-4809$.

The authors declare no competing financial interest. 